\title{
Prognostic Value of Autophagy-related Proteins in Human Gastric Cancer
}

This article was published in the following Dove Press journal:

Cancer Management and Research

\section{Minmin $\mathrm{Wu}\left(\mathbb{D}^{\prime}\right.$ \\ Bicheng Chen' \\ Xiaodong $\mathrm{Pan}^{2}$ \\ Jiadong $\mathrm{Su}^{3}$}

'Key Laboratory of Diagnosis and Treatment of Severe Hepato-Pancreatic Diseases of Zhejiang Province, The First Affiliated Hospital of Wenzhou Medical University, Wenzhou, Zhejiang Province 325000, People's Republic of China; ${ }^{2}$ Department of Transplantation Laboratory, The First Affiliated Hospital of Wenzhou Medical University, Wenzhou, Zhejiang Province 325000, People's Republic of China; ${ }^{3}$ Department of Traumatology, The First Affiliated Hospital of Wenzhou Medical University, Wenzhou, Zhejiang Province 325000, People's Republic of China
Correspondence: Jiadong Su Department of Traumatology, The First Affiliated Hospital of Wenzhou Medical University, Wenzhou, 325000 Zhejiang

Province, People's Republic of China Tel +8615067839162

Email361603059@qq.com
Purpose: Autophagy-related proteins (ATG) play a crucial role in autophagy. Recently, the functions of autophagy in cancer have been gathering attention. However, the prognostic value of ATGs in gastric cancer (GC) has not been explored.

Methods: The Kaplan-Meier plotter (KM plotter) online database was used to examine the value of ATGs gene expression levels in overall survival (OS) prediction in GC patients with different clinical stage, differentiation, gender, HER2 status, and therapeutic strategy. In vitro experiments applied VE-822, an effective GC treatment, to assess cell migration and proliferation in gastric mucosa epithelial cells, and real-time PCR was used to measure alterations of autophagy-related gene expression.

Results: High $A T G 3, A T G 4 C, A T G 5$, and $A T G 10$ mRNA levels were associated with good OS, while increased $A T G 4 B, A T G 7, A T G 12, A T G 16 L 1$, and TECPR1 mRNA levels related to unfavorable OS in patients with GC. ATG12 overexpression had different effects on OS due to high levels of heterogeneity. High $A T G 12$ expression was correlated with good OS in female patients with GC and with bad OS for male patients. Additionally, the increased ATG12 expression was more likely to get a satisfactory OS in patients who underwent surgery alone but was associated with poor OS for patients treated with 5-FU adjuvant. In addition, elevated TECPRI expression was related to favorable OS for patients with poorly differentiated type, while for patients with moderate differentiation, it was relevant to poor OS. The in vitro experiments showed that berzosertib could significantly inhibit the migration and proliferation of human gastric mucosa epithelial cells, and further real-time PCR assessment of ATG expressions partially coincided with the bioinformation analysis above. Conclusion: These results indicate that individual ATGs have unique prognostic significance interpreted using Kaplan-Meier plotter analysis and in vitro experiments, and this may help guide clinical therapeutic strategy and promote OS by individualizing therapy for GC patients. Keywords: autophagy-related proteins, prognostic values, gastric cancer, overall survival

\section{Introduction}

According to statistics from World Health Organization, gastric cancer (GC) is the fifth most common cancer and greatly impacts human health. ${ }^{1}$ Although the mortality rate for patients with GC has declined over the past three decades, it remains high and GC remains the third highest cause of cancer-related death globally. $^{2}$ In China approximately 679,000 new cases of GC were diagnosed in 2015, and about 490,000 patients with GC died. ${ }^{3,4}$ Therefore, it is necessary to identify the biomolecules to improve its diagnosis and overall survival (OS).

Autophagy is a metabolic and cell protective process that sustains nutrient supply when following starvation or harm. Autophagy achieves this by digesting impaired proteins and organelles, or some pathogens, to recycle nutrients to 
generate ATP or other proteins and organelles. ${ }^{5}$ It is important for organismal maturation, saves resources, and regulates pathophysiology. ${ }^{6,7}$ However, this protective characteristic seems suspicious in gastric cancer. One recent study revealed that miR-5100 was able to inhibit tumorigenesis through propelling apoptosis and suppressing autophagy by targeting $C A A P 1$ the apoptosis inhibitor and autophagy promotor, and when applying the inhibitor of miR-5100, autophagy was then upregulated, and the tumor grew faster. ${ }^{8}$ Therefore, in fact, autophagy plays dual roles in cancer based on the cancer type, stage, and genetic background of the patient. Initially, autophagy acts as a tumor suppressor by reducing oncogenic protein p62, and assists in eliminating impaired organelles or DNA to stop further cellular injury and cancer development. 9,10 Later, autophagy can protect tumors from injuries caused by nutrient shortage, radiation, and chemotherapeutics, and strengthen tumor metabolism and growth, leading to drug resistance. ${ }^{10,11}$

Autophagy-related proteins (ATG) are crucial components in the autophagy system. In total there are 38 kinds of ATGs ${ }^{12,13}$ that participate in almost every step of autophagy, including initiation, phagophore expansion, autophagosome assembly and formation, fusion with lysosomes, and digestion. ${ }^{14}$ Therefore, aberrant autophagic gene expression might result in the digestion of important endogenic cytokines or regulatory proteins that function as tumor promotors. One of previous study reported that autophagy may be involved in the progression of AQP3-mediated cisplatin chemotherapeutic resistance in GC cells, while, the autophagy inhibitor, chloroquine, can intensify the effects of, and sensitivity to, cisplatin in GC cells. ${ }^{15,16}$ High Beclin1 expression is an independent predictor of poor prognosis and poor OS in patients with GC. ${ }^{17}$ Furthermore, LC3, which is related to autophagosome biosynthesis, is expressed at higher levels in the center of GC tumors than it is at the edges and can be considered an advanced indicator in the early stage of GC. ${ }^{18}$ Biomarkers play significant roles in cancer diagnosis, determination of therapeutic strategy, and prognosis. Accumulating data in animal models or from clinical studies indicate expression of ATGs, including $A T G 2 B, A T G 5, A T G 9 B, A T G 12$, and $A T G 16 L 1$ are closely related to GC and may influence autophagy in the development and progression of GC. ${ }^{19-22}$ However, systematic clinical evidence and analysis is required for the application of treatments with improved efficacy to achieve better survival outcomes.
In this study, the autophagic gene expression was examined to determine its prognostic significance for GC patients. Specifically, ATG3, ATG4B, ATG4C, ATG5, ATG7, ATG10, $A T G 12, A T G 16 L 1$, and TECPR1 expressions were analyzed using a database Kaplan-Meier plotter (KM plotter) and the corresponding in vitro experiment was conducted as a verification for the theory obtained from the bioinformatic analysis. This research is hopefully to provide a new clinical treatment direction and significantly contribute to reducing mortality in patients with GC.

\section{Materials and Methods Prognostic Value Analysis of ATGs}

The recently developed Kaplan-Meier plotter (http:// kmplot.com/analysis) was used to assess the association between expression of ATG genes and overall survival (OS) in patients with GC. The candidate genes examined in this study were $A T G 3, A T G 4 B, A T G 4 C, A T G 7$, ATG10, ATG12, ATG16L1, and TECPR1. Clinical characteristics, including tumor pathological stage, HER2 expression status, treatment strategy, gender, and differentiation were included and considered crucial factors for OS in combination with the expression of different ATGs. Gene expression levels in the Kaplan-Meier plot surpassing or below the median were classified as high and low expression, respectively, and the test value was ranked as risk by referring under main plot. Hazard ratios, 95\% confidence intervals, and $\log$ rank $P$ were calculated. $P<0.05$ was considered statistically significant.

\section{Cell Culture and Regents}

Human gastric mucosa epithelial cell lines (GES 1) were purchased from the American Type Culture Collection (ATCC, Manassas, VA, USA). The cells were cultured in DMEM (GENOM, Hangzhou, China), containing 10\% FBS (Thermo Fisher Scientific, Waltham, MA, USA), and $1 \%$ penicillin-streptomycin (Gibco/Thermo Fisher Scientific) at $37^{\circ} \mathrm{C}$ in a humidified atmosphere with $5 \%$ $\mathrm{CO}_{2}$. The ATR inhibitor, VE-822, was purchased from Selleck Chemicals (Houston, TX, USA).

\section{Colony Formation Assay}

Cells were seeded into six-well plates at 500-1000 cells/ well. When cells formed colonies visible to the naked eye, VE-822 was added at the indicated doses for two days. 
The results were visualized by crystal violet staining and counted for statistical analysis.

\section{Migration Assay}

Cells were equally distributed into six-well plates and crystal pipette tips were applied to scratched in the middle of the well to make a blank linear gap when cells grew to a proper density. The cells were washed with PBS to remove nonadherent cells. VE-822 was added and incubated with the cells for $24 \mathrm{~h}$. During this period, cells could grow into blank area and filled the gap. The width of the liner gap in each well was observed under a microscope and images were captured.

\section{Real-time Polymerase Chain Reaction (Real-time PCR)}

Real-time PCR was performed to measure ATG gene expression levels. Gene specific primers were designed and are listed in in Table 1. Gene expression in cells treated with 0,4 , and $6 \mu \mathrm{M}$ VE-822 were assessed. RNA was isolated from cells using a total RNA Kit (Tiangen),

Table I Primers Used in RT-qPCR

\begin{tabular}{|c|c|c|}
\hline Gene & Primer & Sequence \\
\hline GAPDH & $\begin{array}{l}\text { Forward } \\
\text { Reverse }\end{array}$ & $\begin{array}{l}\text { TGACTTCAACAGCGACACCCA } \\
\text { CACCCTGTTGCTGTAGCCAAA }\end{array}$ \\
\hline ATG3 & $\begin{array}{l}\text { Forward } \\
\text { Reverse }\end{array}$ & $\begin{array}{l}\text { GACCCCGGTCCTCAAGGAA } \\
\text { TGTAGCCCATTGCCATGTTGG }\end{array}$ \\
\hline ATG4B & $\begin{array}{l}\text { Forward } \\
\text { Reverse }\end{array}$ & $\begin{array}{l}\text { ATGGACGCAGCTACTCTGAC } \\
\text { TTTTCTACCCAGTATCCAAACGG }\end{array}$ \\
\hline ATG4C & $\begin{array}{l}\text { Forward } \\
\text { Reverse }\end{array}$ & $\begin{array}{l}\text { ACCCCAACAATTTCTCTGAAGG } \\
\text { GTCCATACCAATCTCCTGCTTTT }\end{array}$ \\
\hline ATG5 & $\begin{array}{l}\text { Forward } \\
\text { Reverse }\end{array}$ & $\begin{array}{l}\text { AGAAGCTGTTTCGTCCTGTGG } \\
\text { AGGTGTTTCCAACATTGGCTC }\end{array}$ \\
\hline ATG7 & $\begin{array}{l}\text { Forward } \\
\text { Reverse }\end{array}$ & $\begin{array}{l}\text { CAGTTTGCCCCTTTTAAGTAGTGC } \\
\text { CCAGCCGATACTCGTTCAGC }\end{array}$ \\
\hline ATGIO & $\begin{array}{l}\text { Forward } \\
\text { Reverse }\end{array}$ & $\begin{array}{l}\text { AGACCATCAAAGGACTGTTCTGA } \\
\text { GGGTAGATGCTCCTAGATGTGAC }\end{array}$ \\
\hline ATG $/ 2$ & $\begin{array}{l}\text { Forward } \\
\text { Reverse }\end{array}$ & $\begin{array}{l}\text { CTGCTGGCGACACCAAGAAA } \\
\text { CGTGTTCGCTCTACTGCCC }\end{array}$ \\
\hline ATGI6LI & $\begin{array}{l}\text { Forward } \\
\text { Reverse }\end{array}$ & $\begin{array}{l}\text { CTTAACCCTGCGGTCCAT } \\
\text { СТСTTCСTTCCCAGTCCC }\end{array}$ \\
\hline TECPRI & $\begin{array}{l}\text { Forward } \\
\text { Reverse }\end{array}$ & $\begin{array}{l}\text { GGGCTCGCTCACGAAGATG } \\
\text { CCTGAATGAGGTGGTGGCG }\end{array}$ \\
\hline
\end{tabular}

Abbreviation: ATG, autophagy-related gene. A following the manufacturer's instructions. The High Capacity cDNA Reverse Transcription Kit (Thermo Fisher Scientific, Inc.) was used to generate cDNA. An ABI PRISM 7500FAST PCR Sequence Detection System (Applied Biosystems, Foster City, CA, USA) was also used.

\section{Statistical Analysis}

All the assays were repeated more than three times and the corresponding data were analyzed using GraphPad Prism 8.2.0 (GraphPad Software lnc., San Diego, USA). One-way ANOVA test was used to compare means and $P<0.05$ was considered significant.

\section{Results \\ GC Prognostic Values of Autophagy-related Proteins}

ATGs were all successfully retrieve from http://www. kmplot.com/. ATG3 was detected with the Affymetrix ID: 221492_s_at. OS curves were plotted for all patients with gastric cancer $(\mathrm{n}=876)$ (Figure 1A), intestinal cancer $(\mathrm{n}=320)$ (Figure 1B), diffuse cancer $(\mathrm{n}=241)$ (Figure 1C), and mixed cancer $(\mathrm{n}=32)$ (Figure 1D). Increased $A T G 3$ mRNA expression was related to satisfactory $\mathrm{OS}$ in all patients with $\mathrm{GC}(\mathrm{HR}=0.51,95 \% \mathrm{CI}: 0.41-0.63, P=2.2 \mathrm{e}$ $-10)$, including patients with intestinal cancer $(\mathrm{HR}=0.43$, 95\%CI: $0.31-0.59, P=1.5 \mathrm{e}-07)$, diffuse cancer $(\mathrm{HR}=0.45$, 95\%CI: $\quad 0.31-0.65, \quad P=1.8 \mathrm{e}-05)$, and mixed cancer (HR $=0.32,95 \% \mathrm{CI}: 0.11-0.92, P=0.026$ ).

The prognostic significance of $A T G 4 B$ mRNA expression was evaluated in the database (Affymetrix ID is 204902_s_at). OS curves revealed a correlation between $A T G 4 B$ mRNA expression level and a poor OS for all patients with gastric cancer $(\mathrm{HR}=1.8,95 \% \mathrm{CI} 1.52-2.13$, $P=8.2 \mathrm{e}-12$; Figure $2 \mathrm{~A}$ ), including those with intestinal cancer $(\mathrm{HR}=2.16,95 \% \mathrm{CI}: 1.57-2.99, P=1.6 \mathrm{e}-06$; Figure 2B), diffuse cancer patients (HR=1.49, 95\%CI: 1.06-2.09, $P=0.022$; Figure 2C), and in mixed cancer patients (HR=3.04, 95\%CI: 0.97-9.54, $P=0.046$; Figure 2D).

High expression of $A T G 4 C$ (Affymetrix ID is 228190_at) mRNA was related to good $\mathrm{OS}$ in all patients with $\mathrm{GC}$ $(\mathrm{HR}=0.63, \quad 95 \% \mathrm{CI}: \quad 0.5-0.8, \quad P=0.00014$; Figure $3 \mathrm{~A})$. Histological subtype results showed that increased $A T G 4 C$ mRNA levels were related to good OS in patients with intestinal cancer $(\mathrm{HR}=0.45,95 \% \mathrm{CI}$ : $0.31-0.65, P=1 \mathrm{e}-05$; Figure 3B). However, ATG4C mRNA expression level was not related to $\mathrm{OS}$ in patients with diffuse cancer $(\mathrm{HR}=0.75,95 \%$ CI: $0.53-1.08, P=0.12$; Figure $3 \mathrm{C})$ or mixed cancer $(\mathrm{HR}=3.29$, 95\%CI: 0.73-14.91, $P=0.1$; Figure 3D). 
A All B Intestinal C Diffuse $\quad$ D Mixed
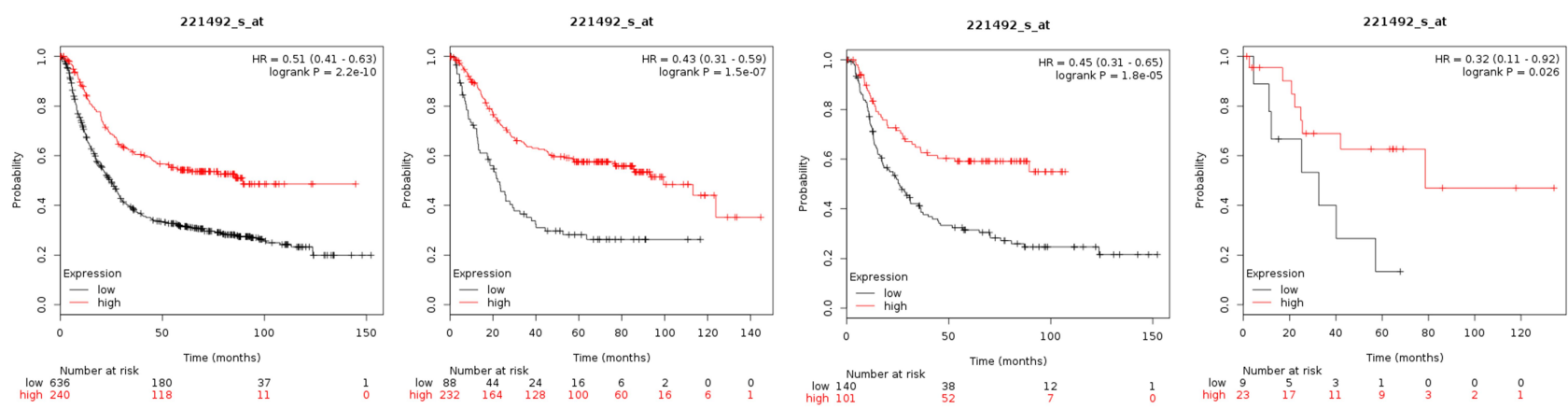

Figure I The prognostic significance of ATG3 expression in gastric cancer. The prognostic value of autophagy-related protein 3 expression in www.kmplot.com. Affymetrix ID for ATG3 is 221492_s_at, overall survival curves were plotted for all patients (A), and for those with intestinal type (B), diffuse type (C), and mixed type cancers (D).

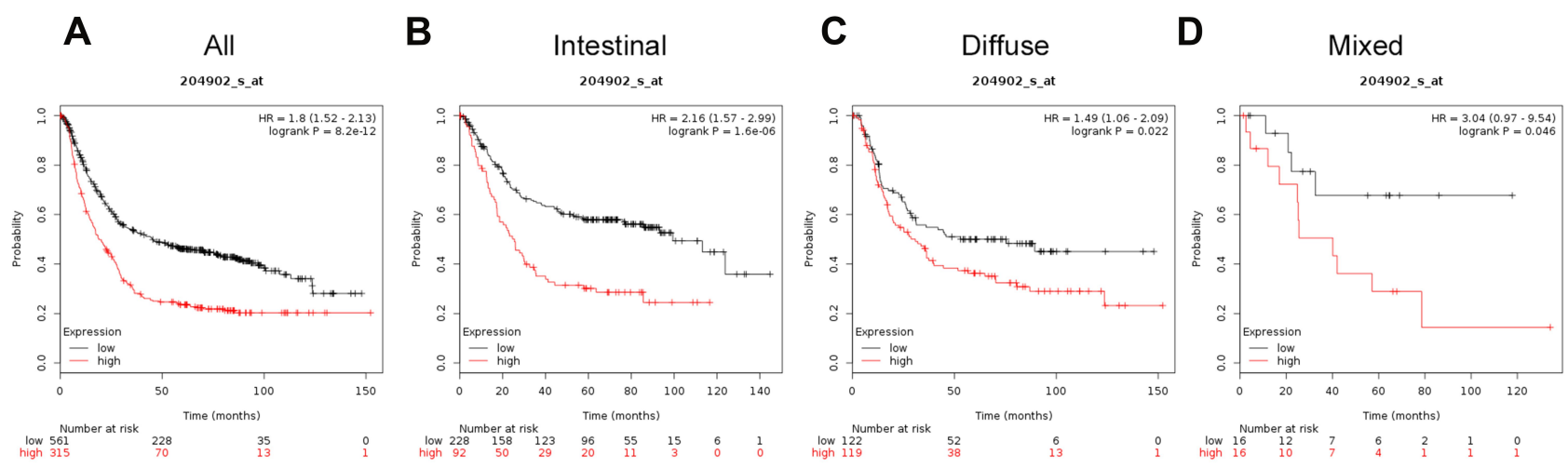

Figure 2 The prognostic significance of ATG4B expression in gastric cancer. The prognostic value of autophagy-related protein 4B expression in www.kmplot.com. Affymetrix ID for ATG4B is 204902_s_at, overall survival curves were plotted for all patients (A), and for those with intestinal type (B), diffuse type (C), and mixed type cancers (D).
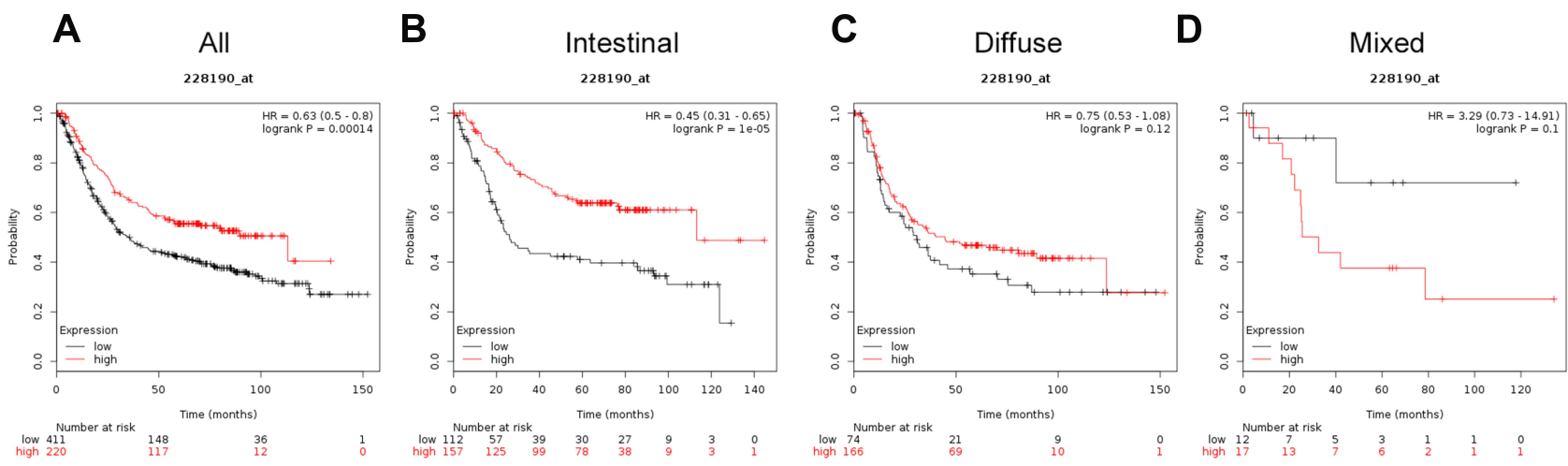

Figure 3 The prognostic significance of $A T G 4 C$ expression in gastric cancer. The prognostic value of autophagy-related protein $4 C$ expression in www.kmplot.com. Affymetrix ID for ATG4C is $228190 \_$s_at, overall survival curves were plotted for all patients (A), and for those with intestinal type (B), diffuse type (C), and mixed type cancer (D).

Similar results were observed for $A T G 5$ (Affymetrix ID is 202512_s_at). Increased ATG5 mRNA expression was significantly correlated with favorable OS for all patients with $\quad \mathrm{GC} \quad(\mathrm{HR}=0.61,95 \% \mathrm{CI}: \quad 0.51-0.73, \quad P=7.7 \mathrm{e}-08$; Figure $4 \mathrm{~A})$ and intestinal cancer $(\mathrm{HR}=0.42,95 \% \mathrm{CI}: 0.3$
$-0.59, P=3.9 \mathrm{e}-07$; Figure 4B). However, ATG5 mRNA expression was not correlated with OS in patients with diffuse cancer patients ( $\mathrm{HR}=0.78,95 \% \mathrm{CI}: 0.56-1.1$, $P=0.16$ Figure $4 \mathrm{C})$ or mixed cancer $(\mathrm{HR}=2.89,95 \% \mathrm{CI}$ : $0.65-12.9, P=0.15$; Figure 4D). 

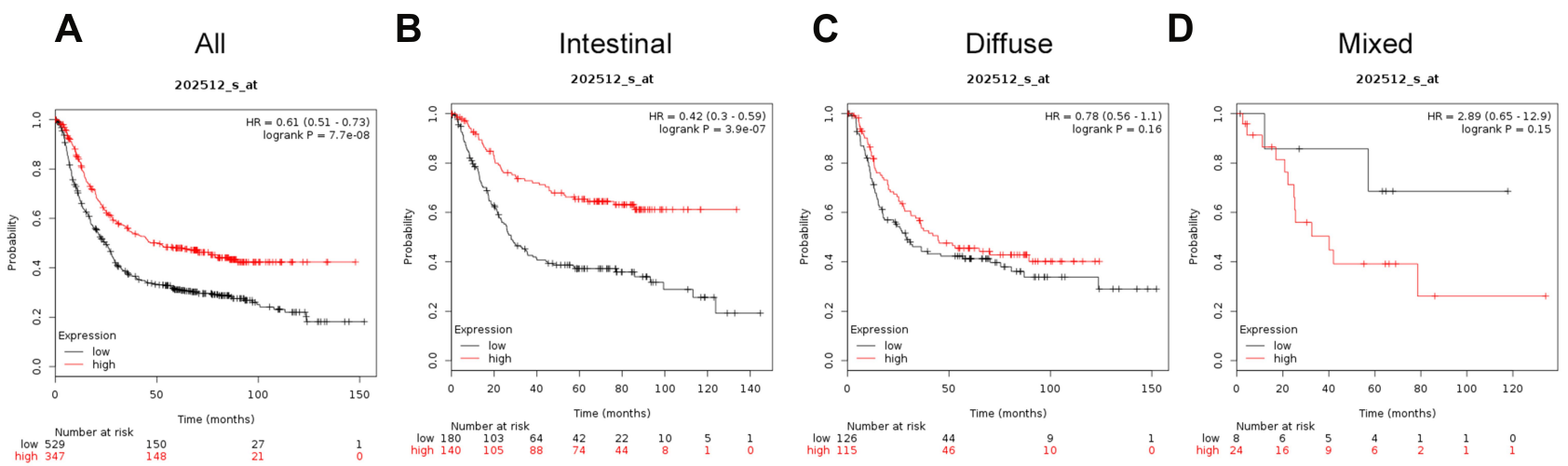

Figure 4 The prognostic significance of ATG5 expression in gastric cancer. The prognostic value of autophagy-related protein 5 expression in www.kmplot.com. Affymetrix ID for ATG5 is 2025I2_s_at, overall survival curves were plotted for all patients (A), and for those with intestinal type (B), diffuse type (C), and mixed type cancers (D).

The prognostic value of $A T G 7$ (Affymetrix ID is 218673_s_at) was assessed using information in the database (Figure 5). ATG7 mRNA expression levels were associated with inferior OS for all patients with GC (HR=1.47, 95\%CI: $1.24-1.74, P=1.1 \mathrm{e}-05)$, intestinal cancer $(\mathrm{HR}=1.82,95 \% \mathrm{CI}: 1.33-2.5, P=0.00018)$, and diffuse cancer $(\mathrm{HR}=1.86,95 \% \mathrm{CI}: 1.29-2.67, P=0.00076)$, but not in those with mixed cancer $(\mathrm{HR}=1.94,95 \% \mathrm{CI}: 0.69$ $-5.44, P=0.2$ ).

The prognostic value of ATG10 (Affymetrix ID is 218214_at) was assessed using the database (Figure 6). The OS curves revealed a connection between ATG10
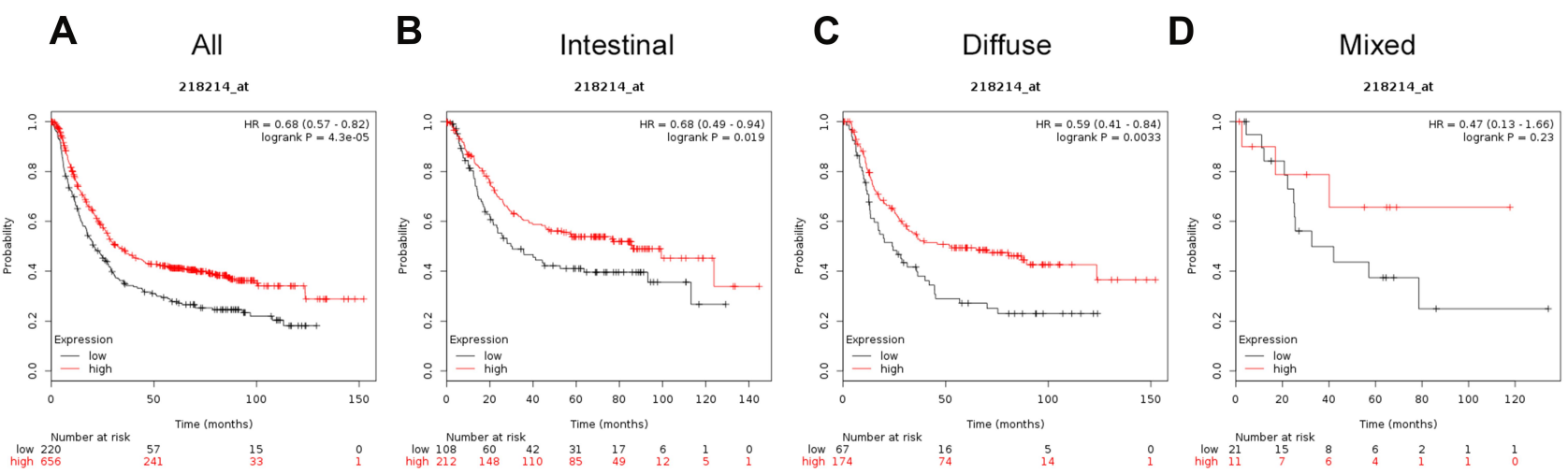

Figure 5 The prognostic significance of ATG7 expression in gastric cancer. The prognostic value of autophagy-related protein 7 expression in www.kmplot.com. Affymetrix ID for ATG7 is 218673_s_at, overall survival curves were plotted for all patients (A), and for those with intestinal type (B), diffuse type (C), and mixed type cancers (D).

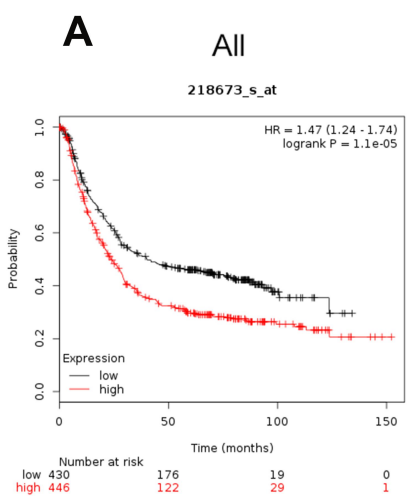

B

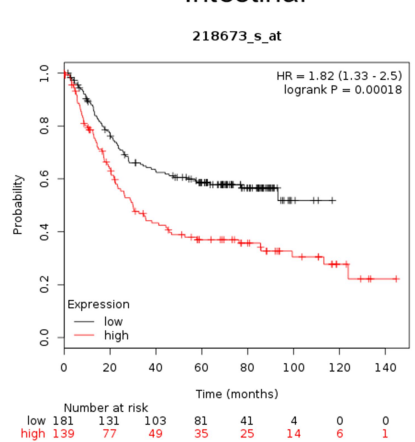

C

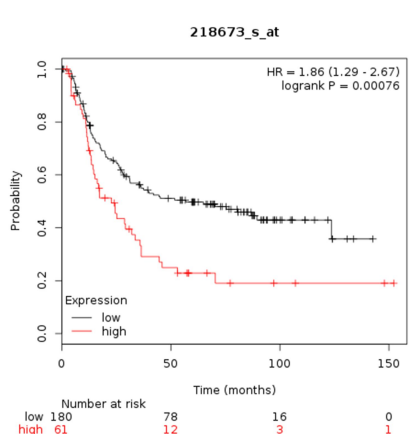

D

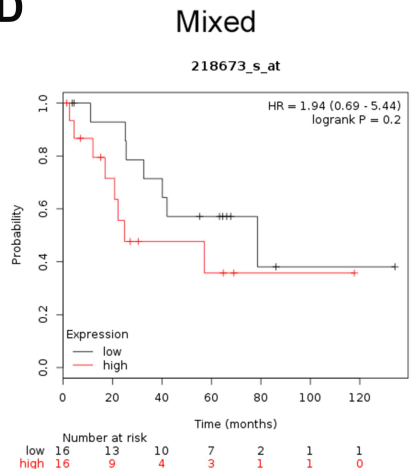

Figure 6 The prognostic significance of ATGIO expression in gastric cancer. The prognostic value of autophagy-related protein 10 expression in www.kmplot.com. Affymetrix ID for ATGIO is 218214 _s_at, OS curves were plotted for all patients (A), and for those with intestinal type (B), diffuse type (C), and mixed type cancers (D). 
mRNA expression and good OS for all patients with GC (HR=0.68, 95\%CI: $0.57-0.82, P=4.3 \mathrm{e}-05)$, intestinal cancer $(\mathrm{HR}=0.68,95 \% \mathrm{CI}: 0.49-0.94, P=0.019)$, diffuse cancer $(\mathrm{HR}=0.59,95 \% \mathrm{CI}: 0.41-0.84, P=0.0033)$ but for those with mixed cancer $(\mathrm{HR}=0.47,95 \% \mathrm{CI}: 0.13-1.66, P=0.23)$.

The prognostic value of ATG12 (Affymetrix ID for ATG12 is 213026_at) was assessed using the database (Figure 7). High ATG12 mRNA expression was associated with poor $\mathrm{OS}$ in all patients with $\mathrm{GC}(\mathrm{HR}=1.31,95 \% \mathrm{CI}$ : 1.09-1.56, $P=0.0031$ ) and patients with diffuse subtype GC $(\mathrm{HR}=1.78,95 \% \mathrm{CI}: 1.26-2.5, P=0.00087)$ but was not associated with $\mathrm{OS}$ in patients with intestinal cancer ( $\mathrm{HR}=1.42,95 \% \mathrm{CI}: 1-2.01, P=0.051)$, or mixed cancer $(\mathrm{HR}=0.58,95 \% \mathrm{CI}: 0.18-1.85, P=0.35)$.

The prognostic value of ATG16L1 mRNA (Affymetrix ID: 232612 _s_at) was assessed by plotting OS curves for all patients with GC (Figure 8A), intestinal cancer (Figure 8B), diffuse cancer (Figure 8C), and mixed cancer
(Figure 8D). High ATG16L1 mRNA expression was related to unfavorable $\mathrm{OS}$ for all $\mathrm{GC}$ patients $(\mathrm{HR}=1.43$, 95\%CI: $1.15-1.77, \quad P=0.0012)$ and intestinal cancer patients $(\mathrm{HR}=1.83,95 \% \mathrm{CI}: 1.25-2.69, P=0.0016)$. For patients with diffuse and mixed cancer types, OS was independent of expression of ATG16L1 mRNA levels (for patients with diffuse cancer $(\mathrm{HR}=0.83,95 \% \mathrm{CI}$ : 0.58 $-1.19, P=0.3)$, and for patients with mixed cancer types $(\mathrm{HR}=1.92$, 95\%CI: $0.59-6.25, P=0.27)$.

The Affymetrix ID for TECPR1 is 227580_s_at. Increased TECPR1 mRNA expression is related to poor OS for all patients with GC patients $(\mathrm{HR}=1.49$, 95\%CI: 1.14-1.95, $P=0.0031$; Figure $9 \mathrm{~A})$ and intestinal cancer ( $\mathrm{HR}=1.86,95 \% \mathrm{CI}: 1.2-2.86, P=0.0044$; Figure 9B). However, TECPR1 mRNA overexpression in patients with diffuse $(\mathrm{HR}=1.23,95 \% \mathrm{CI}$ : $0.82-1.84, \quad P=0.32$; Figure 9C) and mixed cancer $(\mathrm{HR}=5.43$, 95\%CI: 0.7 $-42.33, P=0.071$; Figure 9D) was not correlated with OS.
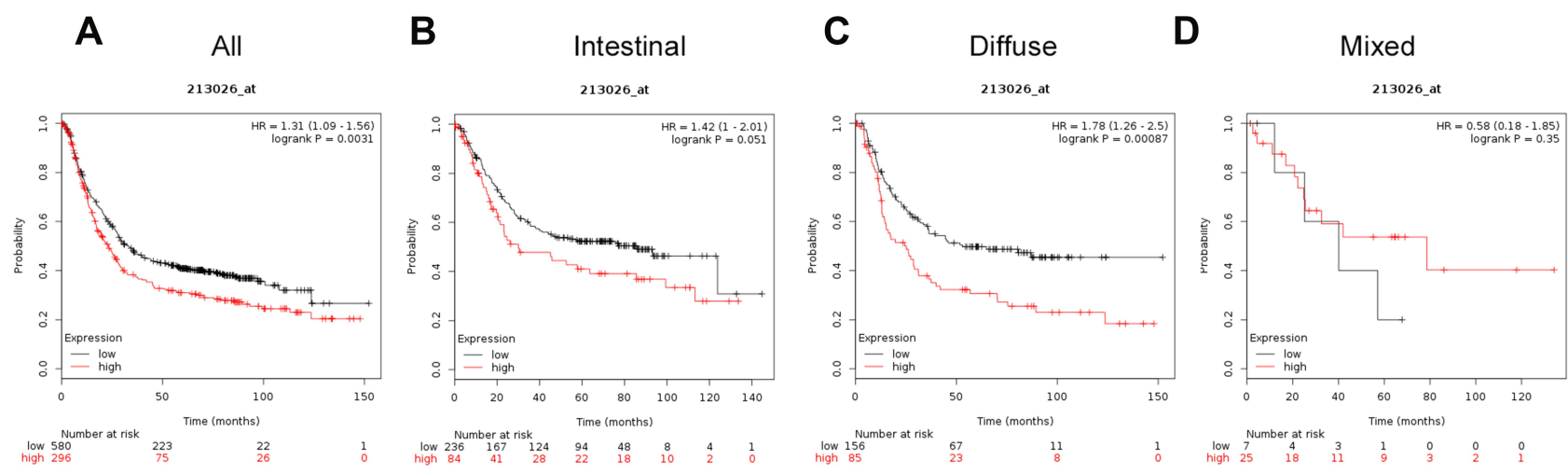

Figure 7 The prognostic significance of ATG/2 expression in gastric cancer. The prognostic value of autophagy-related protein 12 expression in www.kmplot.com. Affymetrix ID for ATGI2 is 213026 s_at, overall survival curves were plotted for all patients (A), and for those with intestinal type (B), diffuse type (C), and mixed type cancers (D).
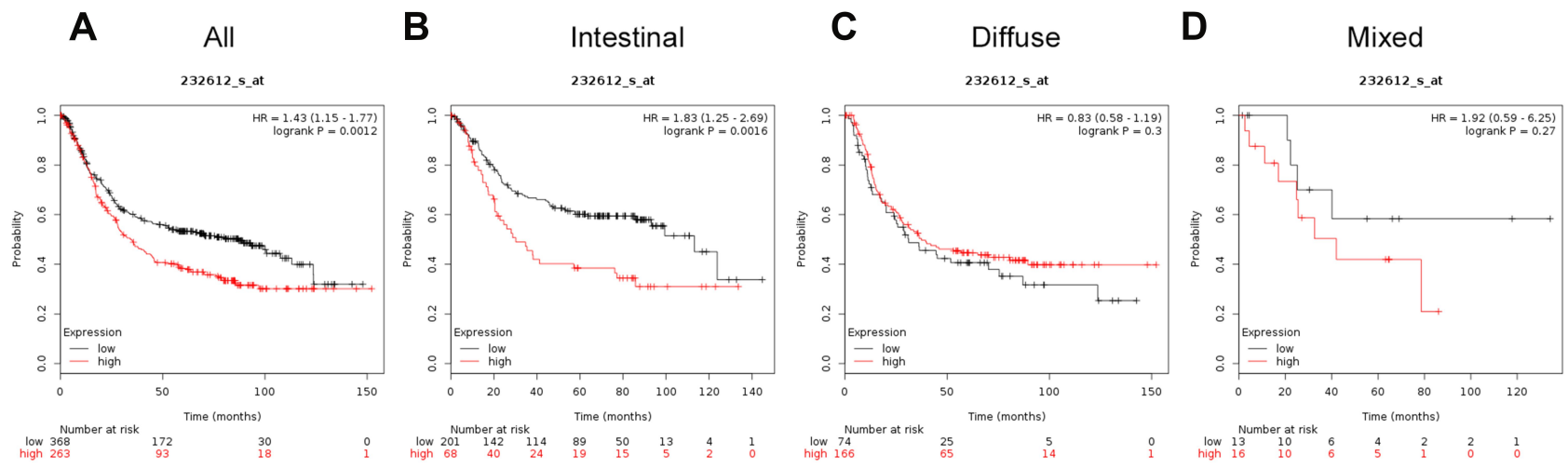

Figure 8 The prognostic significance of ATGI6LI expression in gastric cancer. The prognostic value of autophagy-related protein I6LI expression in www.kmplot.com. Affymetrix ID for ATG I6LI is 2326I2_s_at, overall survival curves were plotted for all patients (A), and for those with intestinal type (B), diffuse type (C), and mixed type cancers (D). 

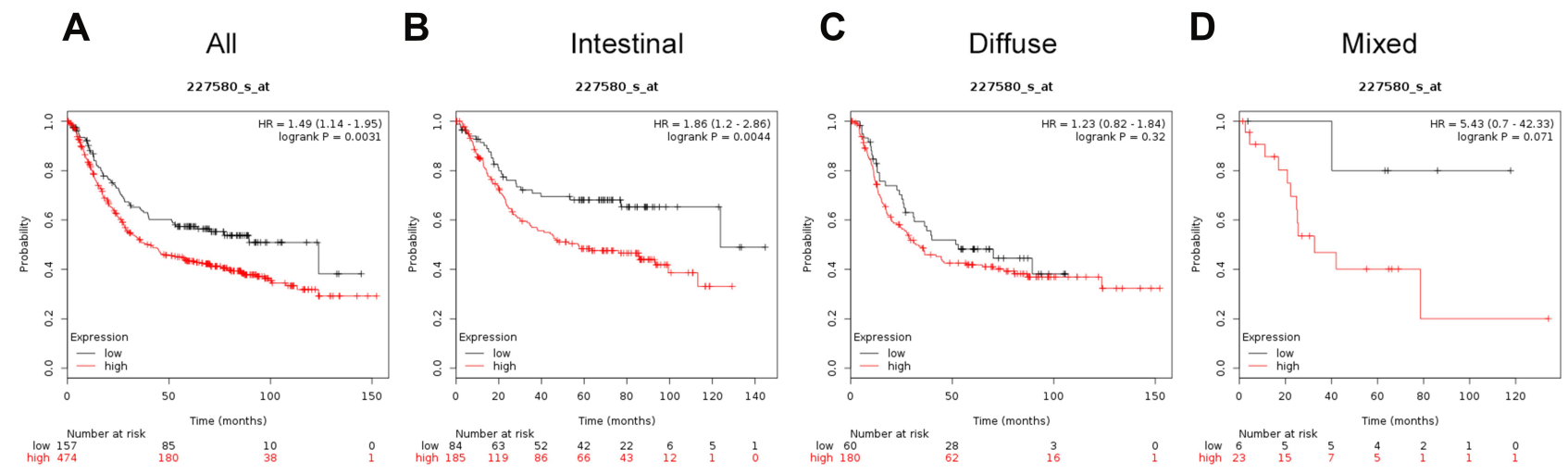

Figure 9 The prognostic significance of TECPRI expression in gastric cancer. The prognostic value of tectonin b-propeller repeat containing I expression in www.kmplot. com. Affymetrix ID for TECPRI is $227580 \_$s_at, overall survival curves were plotted for all patients (A), and for those with intestinal type (B), diffuse type (C), and mixed type cancers (D).

We also assessed the correlation between the expression of UBL conjugation system genes and GC patient other clinicopathological features, including pathological stage (Table 2), HER2 status (Table 3), treatment strategy (Table 4), gender (Table 5), and differentiation (Table 6). Increased expression of $A T G 3$ is correlated with satisfactory OS in patients with GC in stages I, III, and IV (Table 2). Increased $A T G 4 C$ and $A T G 10$ mRNA expression correlates with improved OS in patients with stages I and III GC. Furthermore, high ATG5 and ATG12 expressions correlate with good OS only in patients with stage III GC. Patients with poor OS exhibit overexpression of $A T G 4 B$ (stage I and stage III), $A T G 7$ (stage III), ATG12 (stage IV), ATG16L1 (stage II and stage III), and TECPRI (stage III).

The relationship between the expression of ATGs and $H E R 2$ gene status and prognosis in patients with GC was assessed (Table 3). Patients with negative HER2 gene status and high levels of $A T G 3$ and $A T G 4 C$ expressions have favorable OS. Conversely, negative HER 2 status and increased TECPR1 mRNA levels are associated with poor OS in patients with GC. HER2 gene status does not appear to influence OS in patients with GC. Increased $A T G 5$ and $A T G 10$ expression always correlates with improved OS, while increased $A T G 4 B, A T G 7$, $A T G 12$, and $A T G 16 L 1$ expression is generally correlated with an unfavorable OS.

We examined the effects of treatment in patients with GC with different UBL conjugation system gene expression levels (Table 4). When patients received surgery alone, $A T G 3, A T G 4 C, A R G 5$, and $A T G 10$ overexpression was usually related to favorable OS, and $A T G 12$ and ATG16L1 overexpression generally resulted in unfavorable OS. When patients were treated with adjuvant, those with high levels of $A T G 3$ (other adjuvant), ATG5 (5-FU), and ATG12 (5-FU) expression were associated with good OS, but patients with high $A T G 4 C$ expression were unable to achieve good OS. Additionally, increased $A T G 4 B$ expression was always associated with poor OS, irrespective of the treatment received.

The correlation between the expression of UBL conjugation system genes and $\mathrm{OS}$ in patients with GC of different genders was also assessed (Table 5). High levels of ATG3, ATG5, and ATG10 expression was usually associated with good OS in both male and female patients with $\mathrm{GC}$, and high $A T G 4 B$ expression was associated with poor OS. Overexpression of ATG7, ATG12, ATG16L1, and $T E C P R 1$ in male patients was associated with poor OS, and increased $A T G 4 C$ and $A T G 12$ expression correlates with favorable OS only in male and female patients, respectively.

The correlation between ATG gene expression and OS in patients with gastric cancer and different differentiation was analyzed (Table 6). Obvious heterogeneity in ATG gene expression levels was observed. For patients with poorly differentiated gastric cancer, high $A T G 12$ or $A T G 16 L 1$ expression was associated with poor OS, while high TECPR1 expression correlated with good OS. For patients with moderately differentiated GC, increased $A T G 4 C$ expression always correlated with better OS, while increased TECPR1 expression was related to poorer OS. For patients with well differentiated GC, $A T G 4 B$ overexpression was generally correlated with very poor OS, and $A T G 5$ overexpression was associated with good OS. 
Table 2 Correlation of ATG mRNA Expression Levels with OS in Different Pathological Stages in Gastric Cancer Patients

\begin{tabular}{|c|c|c|c|c|}
\hline ATGs & Stages & Cases & HR (95\%Cl) & $P$-value \\
\hline \multirow[t]{4}{*}{ ATG3 } & I & 67 & $0.16(0.02-1.21)$ & $0.042 *$ \\
\hline & II & 140 & $0.5(0.23-1.09)$ & 0.075 \\
\hline & III & 305 & $0.59(0.44-0.8)$ & $0.00042 *$ \\
\hline & IV & 148 & $0.57(0.37-0.88)$ & $0.0097^{*}$ \\
\hline \multirow[t]{4}{*}{ ATG4B } & I & 67 & $3.8(1.37-10.54)$ & $0.0058^{*}$ \\
\hline & II & 140 & I.48 (0.8-2.7I) & 0.21 \\
\hline & III & 305 & $1.89(1.4-2.53)$ & $1.8 \mathrm{e}-05^{*}$ \\
\hline & IV & 148 & $1.26(0.84-1.9)$ & 0.26 \\
\hline \multirow[t]{4}{*}{ ATG4C } & I & 62 & $0.35(0.11-1.08)$ & 0.056 \\
\hline & II & 135 & $1.58(0.8 \mathrm{I}-3.09)$ & 0.18 \\
\hline & III & 197 & $0.42(0.28-0.63)$ & $1.8 \mathrm{e}-05^{*}$ \\
\hline & IV & 140 & $0.65(0.4 I-1.02)$ & 0.061 \\
\hline \multirow[t]{4}{*}{ ATG5 } & I & 67 & $0.47(0.18-1.28)$ & 0.13 \\
\hline & II & 140 & $0.55(0.29-1.04)$ & 0.063 \\
\hline & III & 305 & $0.58(0.42-0.8)$ & $0.00076^{*}$ \\
\hline & IV & 148 & $1.35(0.85-2.13)$ & 0.2 \\
\hline \multirow[t]{4}{*}{ ATG7 } & I & 67 & I.53 (0.56-4.17) & 0.4 \\
\hline & II & 140 & I.8I (0.94-3.48) & 0.072 \\
\hline & III & 305 & I.85 (I.37-2.5I) & $4.8 \mathrm{e}-05^{*}$ \\
\hline & IV & 148 & $1.38(0.94-2.03)$ & 0.096 \\
\hline \multirow[t]{4}{*}{ ATGIO } & I & 67 & $0.27(0.09-0.83)$ & $0.014 *$ \\
\hline & II & 140 & $0.67(0.37-1.23)$ & 0.19 \\
\hline & III & 305 & $0.73(0.55-0.98)$ & $0.034^{*}$ \\
\hline & IV & 148 & $0.73(0.5-1.07)$ & 0.1 \\
\hline \multirow[t]{4}{*}{ ATG 12} & I & 67 & $0.49(0.16-1.52)$ & 0.21 \\
\hline & II & 140 & I.43 (0.75-2.7I) & 0.27 \\
\hline & III & 305 & $0.63(0.46-0.86)$ & $0.0035^{*}$ \\
\hline & IV & 148 & $1.96(1.3-2.95)$ & $0.001 *$ \\
\hline \multirow[t]{4}{*}{ ATGI6LI } & I & 62 & $0.47(0.15-1.45)$ & 0.18 \\
\hline & II & 135 & $2.28(1.19-4.37)$ & $0.01 I^{*}$ \\
\hline & III & 197 & $1.69(1.14-2.49)$ & $0.008^{*}$ \\
\hline & IV & 140 & $0.76(0.48-1.2)$ & 0.24 \\
\hline \multirow[t]{4}{*}{ TECPRI } & I & 62 & $2.08(0.63-6.86)$ & 0.22 \\
\hline & II & 135 & $0.62(0.33-1.17)$ & 0.14 \\
\hline & III & 197 & $1.64(1.02-2.64)$ & $0.04 *$ \\
\hline & IV & 140 & I.4I (0.89-2.25) & 0.14 \\
\hline
\end{tabular}

Note: $* P<0.05$.

Abbreviation: ATG, autophagy-related gene.

\section{VE-822 Suppresses GES I Cell Proliferation and Migration}

Colony formation and cell migration assays were performed to assess the effects of VE-822 treatment on gastric cancer cell proliferation and cell migration. Compared with the control group, cell colony sizes were reduced in a dose-
Table 3 Correlation of ATG mRNA Expression with OS in Gastric Cancer Patients with HER2 Expression Status

\begin{tabular}{|c|c|c|c|c|}
\hline ATGs & HER2 Status & Cases & HR $(95 \% \mathrm{Cl})$ & $P$-value \\
\hline \multirow[t]{2}{*}{ ATG3 } & Negative & 532 & $0.46(0.36-0.59)$ & $1.6 \mathrm{e}-10^{*}$ \\
\hline & Positive & 344 & $0.77(0.6-1)$ & 0.052 \\
\hline \multirow[t]{2}{*}{ ATG4B } & Negative & 532 & I.85 (I.48-2.32) & $5.9 e-08^{*}$ \\
\hline & Positive & 344 & $1.67(1.28-2.18)$ & $0.00013^{*}$ \\
\hline \multirow[t]{2}{*}{ ATG4C } & Negative & 429 & $0.62(0.48-0.82)$ & $0.00059 *$ \\
\hline & Positive & 202 & $0.68(0.45-1.01)$ & 0.055 \\
\hline \multirow[t]{2}{*}{ ATG5 } & Negative & 532 & $0.67(0.53-0.86)$ & $0.0016^{*}$ \\
\hline & Positive & 344 & $0.52(0.39-0.68)$ & $2.3 e-06^{*}$ \\
\hline \multirow[t]{2}{*}{ ATG7 } & Negative & 532 & $1.39(1.11-1.74)$ & $0.0037^{*}$ \\
\hline & Positive & 344 & I.43 (I.08-I.89) & $0.013^{*}$ \\
\hline \multirow[t]{2}{*}{ ATGIO } & Negative & 532 & $0.68(0.54-0.85)$ & $0.00084 *$ \\
\hline & Positive & 344 & $0.7 \mathrm{I}(0.54-0.93)$ & $0.011 *$ \\
\hline \multirow[t]{2}{*}{ ATG 12} & Negative & 532 & $1.35(1.05-1.72)$ & $0.018^{*}$ \\
\hline & Positive & 344 & I.42 (I.I-I.84) & $0.0077^{*}$ \\
\hline \multirow[t]{2}{*}{ ATGI 6LI } & Negative & 429 & $1.57(1.2-2.05)$ & $8 \mathrm{e}-04 *$ \\
\hline & Positive & 202 & $1.74(1.18-2.58)$ & $0.005 I^{*}$ \\
\hline \multirow[t]{2}{*}{ TECPRI } & Negative & 429 & $1.53(1.17-2)$ & $0.0016 *$ \\
\hline & Positive & 202 & $0.68(0.44-1.06)$ & 0.084 \\
\hline
\end{tabular}

Note: $* P<0.05$.

Abbreviation: ATG, autophagy-related gene.

dependent manner in cells treated with VE-822 (Figures 10 and 11). These results indicate that $\mathrm{GC}$ cell proliferation could be inhibited by VE-822. Cell migratory capacity was also suppressed by VE-822 as determined by the narrowed scratch in wells treated with VE-822 (Figure 11).

\section{VE-822 Inhibitory Effects on GC Cells Involves Changes in Autophagy-related Gene Expression}

To explore the influence of autophagy on the observed inhibitory effects of VE-822, ATG gene expression levels were assessed using real-time PCR (Figure 12). Of the nine targets, expression of $A T G 3, A T G 4 B, A T G 4 C$, $A T G 5, A T G 7$, and TCEPR1 showed a declining trend in a VE-822 dose-dependent manner and ATG10, ATG12, and $A T G 16 L 1$ showed no significance in this process. Partially consistent with the Kaplan-Meier plotter database results, $A T G 4 C, A T G 7$, and TCEPR1 expression correlated with poor $\mathrm{OS}$ in patients with $\mathrm{GC}$ patients. However, high $A T G 3, A T G 4 B$, and ATG5 expression, which were associated with good OS, was also reduced 
Table 4 Correlation of ATGs mRNA Expression with OS in Gastric Cancer Patients with Different Treatment Strategy

\begin{tabular}{|c|c|c|c|c|}
\hline ATGs & Treatment & Cases & HR (95\%Cl) & $P$-value \\
\hline \multirow[t]{3}{*}{ ATG3 } & Surgery alone & 380 & $0.75(0.56-1)$ & $0.047^{*}$ \\
\hline & 5-FU adjuvant & 153 & $0.7(0.48-1.02)$ & 0.064 \\
\hline & Other adjuvant & 76 & $0.26(0.1-0.65)$ & $0.0019 *$ \\
\hline \multirow[t]{3}{*}{ ATG4B } & Surgery alone & 380 & $1.37(1.03-1.82)$ & $0.03 I^{*}$ \\
\hline & 5-FU adjuvant & 153 & $1.88(1.32-2.69)$ & $4 e-04 *$ \\
\hline & Other adjuvant & 76 & $3.28(0.96-11.19)$ & $0.045^{*}$ \\
\hline \multirow[t]{3}{*}{ ATG4C } & Surgery alone & 380 & $0.72(0.54-0.98$ & $0.033^{*}$ \\
\hline & 5-FU adjuvant & 34 & I.6I (0.64-4.04) & 0.31 \\
\hline & Other adjuvant & 76 & $2.9(1.2-7.01)$ & $0.013^{*}$ \\
\hline \multirow[t]{3}{*}{ ATG5 } & Surgery alone & 380 & $0.64(0.48-0.86)$ & $0.0025^{*}$ \\
\hline & 5-FU adjuvant & 153 & $0.54(0.37-0.79)$ & $0.0011 *$ \\
\hline & Other adjuvant & 76 & $3.32(0.77-14.32)$ & 0.088 \\
\hline \multirow[t]{3}{*}{ ATG7 } & Surgery alone & 380 & $0.83(0.62-1.11)$ & 0.21 \\
\hline & 5-FU adjuvant & 153 & $\mathrm{I} .4 \mathrm{I}(0.99-2.0 \mathrm{I})$ & 0.055 \\
\hline & Other adjuvant & 76 & $2.32(0.95-5.69)$ & 0.058 \\
\hline \multirow[t]{3}{*}{ ATGIO } & Surgery alone & 380 & $0.67(0.49-0.92)$ & $0.013^{*}$ \\
\hline & 5-FU adjuvant & 153 & $1.37(0.93-2.03)$ & 0.11 \\
\hline & Other adjuvant & 76 & $0.4(0.12-1.36)$ & 0.13 \\
\hline \multirow[t]{3}{*}{ ATG 12} & Surgery alone & 380 & $1.49(1.1-2.02)$ & $0.0 I^{*}$ \\
\hline & 5-FU adjuvant & 153 & $0.54(0.38-0.78)$ & $7 e-04 *$ \\
\hline & Other adjuvant & 76 & $0.73(0.3-1.77)$ & 0.49 \\
\hline \multirow[t]{3}{*}{ ATGI6LI } & Surgery alone & 380 & $1.44(1.07-1.92)$ & $0.014 *$ \\
\hline & 5-FU adjuvant & 34 & $1.97(0.76-5.16)$ & 0.16 \\
\hline & Other adjuvant & 76 & $1.62(0.67-3.92)$ & 0.28 \\
\hline \multirow[t]{3}{*}{ TECPRI } & Surgery alone & 380 & $1.82(1.25-2.65)$ & $0.0016 *$ \\
\hline & 5-FU adjuvant & 34 & $0.43(0.16-1.13)$ & 0.079 \\
\hline & Other adjuvant & 76 & $0.55(0.23-1.34)$ & 0.18 \\
\hline
\end{tabular}

Note: $* P<0.05$.

Abbreviations: 5-FU, 5-fluorouracil; ATG, autophagy-related gene.

after VE-822 treatment. Therefore, the underlining that the mechanism needs to be studied further.

\section{Discussion}

Unique biomarkers express in different cancer stages and cancer type could help with the diagnosis, accurate therapy and evaluation of prognosis. The research of Kim et al found that rich LC3B and p62 normally occurred in GC patients, especially, for tubular adenoma and gastric adenocarcinoma types ${ }^{23}$ and in another study, the researchers reported that LC3A/B and Beclin-1 generally distributed in whole cells for gastric cancer patients with high-risk grade, while, for AMBRA-21 (Beclin-1-regulated autophagy protein-1), it probably only appeared in the
Table 5 Correlation of ATGs mRNA Expression with OS in Gastric Cancer Patients in Different Gender

\begin{tabular}{|c|c|c|c|c|}
\hline ATGs & Gender & Cases & HR (95\%Cl) & $P$-value \\
\hline \multirow[t]{2}{*}{ ATG3 } & Female & 236 & $0.48(0.3 \mathrm{I}-0.72)$ & $0.00034 *$ \\
\hline & Male & 545 & $0.54(0.43-0.68)$ & $9.3 e-08 *$ \\
\hline \multirow[t]{2}{*}{ ATG4B } & Female & 236 & $2.26(1.57-3.24)$ & $6.7 e-06 *$ \\
\hline & Male & 545 & I.84 (I.49-2.28) & $1.4 \mathrm{e}-08^{*}$ \\
\hline \multirow[t]{2}{*}{ ATG4C } & Female & 187 & $0.66(0.43-1.02)$ & 0.062 \\
\hline & Male & 349 & $0.67(0.5-0.9)$ & $0.0076 *$ \\
\hline \multirow[t]{2}{*}{ ATG5 } & Female & 236 & $0.62(0.44-0.88)$ & $0.0068^{*}$ \\
\hline & Male & 545 & $0.55(0.44-0.69)$ & $2.1 e-07^{*}$ \\
\hline \multirow[t]{2}{*}{ ATG7 } & Female & 236 & $1.39(0.98-1.97)$ & 0.061 \\
\hline & Male & 545 & $1.68(1.36-2.09)$ & $1.7 e-06 *$ \\
\hline \multirow[t]{2}{*}{ ATGIO } & Female & 236 & $0.5 \mathrm{I}(0.36-0.72)$ & $9.7 e-05 *$ \\
\hline & Male & 545 & $0.72(0.57-0.9)$ & $0.0037^{*}$ \\
\hline \multirow[t]{2}{*}{ ATG 12} & Female & 236 & $0.56(0.38-0.8)$ & $0.0015^{*}$ \\
\hline & Male & 545 & $1.64(1.29-2.07)$ & $3.1 \mathrm{e}-05^{*}$ \\
\hline \multirow[t]{2}{*}{ ATGI6LI } & Female & 187 & $1.4(0.9-2.19)$ & 0.14 \\
\hline & Male & 349 & $1.36(1.02-1.83)$ & $0.038 *$ \\
\hline \multirow[t]{2}{*}{ TECPRI } & Female & 187 & I.7| (0.98-2.99) & 0.056 \\
\hline & Male & 349 & $1.75(I .22-2.51)$ & $0.002 *$ \\
\hline
\end{tabular}

Note: $* P<0.05$.

Abbreviation: ATG, autophagy-related gene.

nucleus. ${ }^{24}$ Therefore, more biomarkers should be discovered, and the underlying mechanisms involved in the development and progression of GC should be explored to help gastric cancer patients with their diagnosis, therapy, and prognosis.

Autophagy plays a dual role in cancer. On the one hand, autophagy can eliminate the damaged cellular components or entire cells, while on the other hand, the energy or nutrients that come from degradation can provide tumor cells nutrition or be recycled for apoptosis-related protein synthesis of apoptosis relative proteins. Therefore, the ultimate decision of autophagy pathway that closely correlated to OS of gastric cancer patients need to be further studied.

In this study, the prognostic value of autophagy associated gene expression was preliminarily explored by online retrieval from the Kaplan-Meier plotter. GC patients with high $A T G 3, A T G 4 C, A T G 5$, and $A T G 10$ mRNA expression had better OS, while those with high ATG4B, ATG7, ATG12, ATG16L1, and TECPR1 mRNA expression had poorer OS. Then, VE-822 that has previously been testified as effective on gastric cancer $^{25}$ was 
Table 6 Correlation of ATG mRNA Expressions with OS in Gastric Cancer Patients with Different Differentiation

\begin{tabular}{|c|c|c|c|c|}
\hline ATGs & Differentiation & Cases & HR (95\%CI) & $P$-value \\
\hline \multirow[t]{3}{*}{ ATG3 } & Poor & 165 & $0.81(0.52-1.26)$ & 0.35 \\
\hline & Moderate & 67 & $0.59(0.3-1.17)$ & 0.13 \\
\hline & Well & 32 & $0.4(0.13-1.18)$ & 0.086 \\
\hline \multirow[t]{3}{*}{ ATG4B } & Poor & 165 & $1.36(0.84-2.18)$ & 0.2 \\
\hline & Moderate & 67 & I.75 (0.82-3.76) & 0.15 \\
\hline & Well & 32 & $3.33(1.37-8.11)$ & $0.0052^{*}$ \\
\hline \multirow[t]{3}{*}{ ATG4C } & Poor & 126 & I.4I (0.83-2.39) & 0.2 \\
\hline & Moderate & 67 & $0.49(0.26-0.95)$ & $0.03 *$ \\
\hline & Well & 32 & Not available & Not available \\
\hline \multirow[t]{3}{*}{ ATG5 } & Poor & 165 & $1.25(0.84-1.87)$ & 0.27 \\
\hline & Moderate & 67 & $1.94(0.79-4.78)$ & 0.14 \\
\hline & Well & 32 & $0.24(0.07-0.83)$ & $0.015^{*}$ \\
\hline \multirow[t]{3}{*}{ ATG7 } & Poor & 165 & $1.32(0.83-2.1)$ & 0.24 \\
\hline & Moderate & 67 & $0.79(0.41-1.52)$ & 0.47 \\
\hline & Well & 32 & $1.53(0.61-3.82)$ & 0.36 \\
\hline \multirow[t]{3}{*}{ ATGIO } & Poor & 165 & $0.71(0.43-1.16)$ & 0.17 \\
\hline & Moderate & 67 & $1.65(0.85-3.18)$ & 0.13 \\
\hline & Well & 32 & $0.58(0.23-1.5 \mid)$ & 0.26 \\
\hline \multirow[t]{3}{*}{ ATGI 2} & Poor & 165 & $1.53(1.03-2.29)$ & $0.036^{*}$ \\
\hline & Moderate & 67 & $0.77(0.4-1.49)$ & 0.44 \\
\hline & Well & 32 & $0.58(0.25-1.39)$ & 0.22 \\
\hline \multirow[t]{3}{*}{ ATGI $6 \mathrm{LI}$} & Poor & 121 & $1.75(1.06-2.88)$ & $0.027^{*}$ \\
\hline & Moderate & 67 & I.77 (0.89-3.54) & 0.1 \\
\hline & Well & 32 & Not available & Not available \\
\hline \multirow[t]{3}{*}{ TECPRI } & Poor & 121 & $0.49(0.26-0.89)$ & $0.017^{*}$ \\
\hline & Moderate & 67 & $2.83(1.09-7.33)$ & $0.025^{*}$ \\
\hline & Well & 32 & Not available & Not available \\
\hline
\end{tabular}

Note: $* P<0.05$.

Abbreviation: ATG, autophagy-related gene.

employed for the mechanism study. Following VE-822 treatment, expression of $A T G 4 C, A T G 7$, and TCEPR1, all of which are associated with poor OS were decreased. We would like to analyze the potential reasons for these results.

$A T G 3$, the crucial component of the E2-like enzyme in LC3 lipidation, assists $A T G 8$ in phagophore expansion and autocatalyzes itself to form the ATG12-ATG3 complex to maintain mitochondrial homeostasis. ${ }^{26,27}$ In colon cancer, ATG3 gene expression is distinctively elevated by downregulation of miR-431-5p and $A T G 3$ knockdown significantly reduces colon cancer proliferation and invasion. ${ }^{28}$ Additionally, in non-small-cell lung cancer, ATG3 is targeted by lncRNA KCNQ1OT1 and can suppress miR-2045p, while ATG3 upregulation resulted in increased expression of apoptosis-related proteins Bax, cleaved caspase-3, and cleaved caspase- $9 .{ }^{29}$ In GC, ATG3 expression was elevated and was related to favorable OS, especially in combination with negative HER2 status. However, the function of $A T G 3$ differs depending in the type of cancer being examined, indicating that the underlying mechanism needs further study.

ATG5 covalently conjugates with $A T G 12$ and interacts with ATG16 to form a complex involved in autophagosome formation and elongation. ${ }^{30}$ Our results show that high ATG5 expression is associated with better OS in patients with GC. A previous study reported that ATG5 might be cleaved into a $24 \mathrm{~K}$ fragment during apoptosis, and that this fragment functions in the release of cytochrome $\mathrm{c}$ into the cytosol and caspase- 3 cleavage, a crucial 


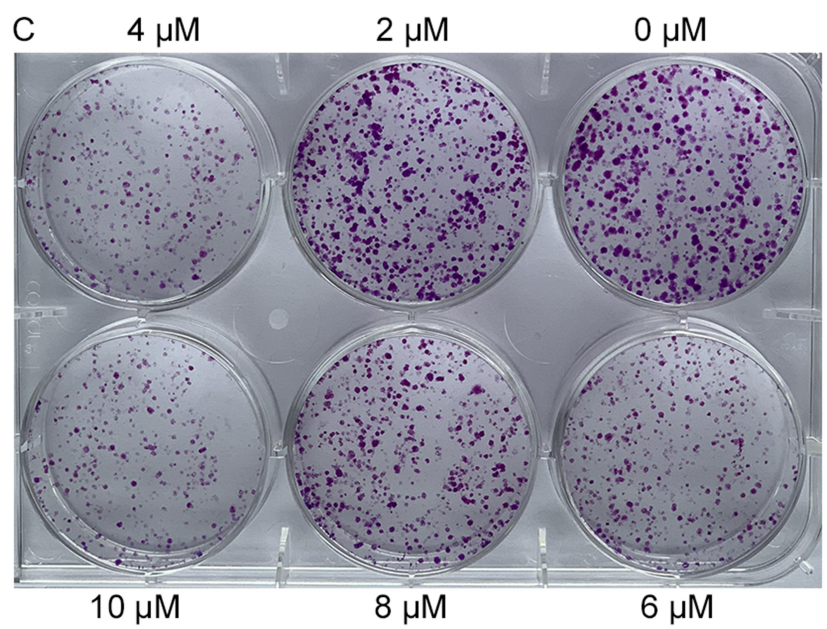

Figure 10 Inhibitory effects of VE-822 on GES I proliferation. Cell colonies was reduced in a dose-dependent manner.

step in apoptosis. ${ }^{31}$ Therefore, increased ATG5 expression may increase susceptibility towards apoptosis stimuli and chemotherapy efficiency. This is consistent with our result that better OS was observed in patients with higher ATG5 expression and who were also treated with 5-FU adjuvant. Additionally, increased ATG5 expression positively correlated with collagen $\mathrm{V}$ gene expression in the airway of asthma pathogenesis, which could promote pulmonary fibrosis development. ${ }^{28}$ Another study found that when suffering injury, quiescent stellate cells of the liver are

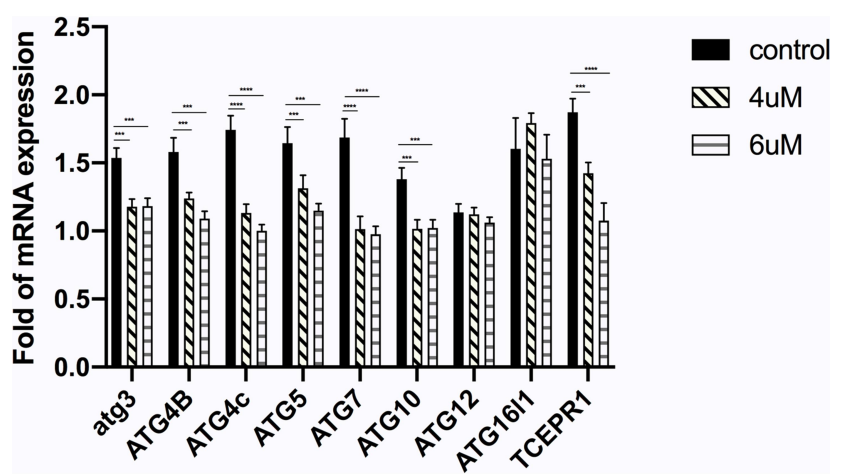

Figure 12 The detection of $m R N A$ expression changes of ATGs by RT-PCR in GES I when treated with VE-822. ATG3, ATG4B, ATG4C,ATG5, ATG7, ATGI0 and TECPRI mRNA levels were downregulated when treated with VE-822. Each data was compared with the control group, $* * * P<0.001$, **** $\mathrm{P}<0.0001$.

activated, ultimately leading to liver fibrosis, and that this process was accelerated by $A T G 5$ and $A T G 7$ taking part in lipid metabolism and energy production. ${ }^{32}$ Taken together, these data imply that $A T G 5$ plays an important role in fibrosis by blocking tumor blood supply and preventing tumor invasion, ultimately leading to good OS in patients with GC.

$A T G 10$ is the E2-like enzyme and, when conjugated with $A T G 12$ and ATG5, takes charge of phagophore expansion. In SW480 colorectal cancer cells, ATG10 overexpression is correlated with upregulated cell proliferation, lymph vascular invasion, and chemoresistance, all of which is reversed by the ATG10 downregulator, miR-

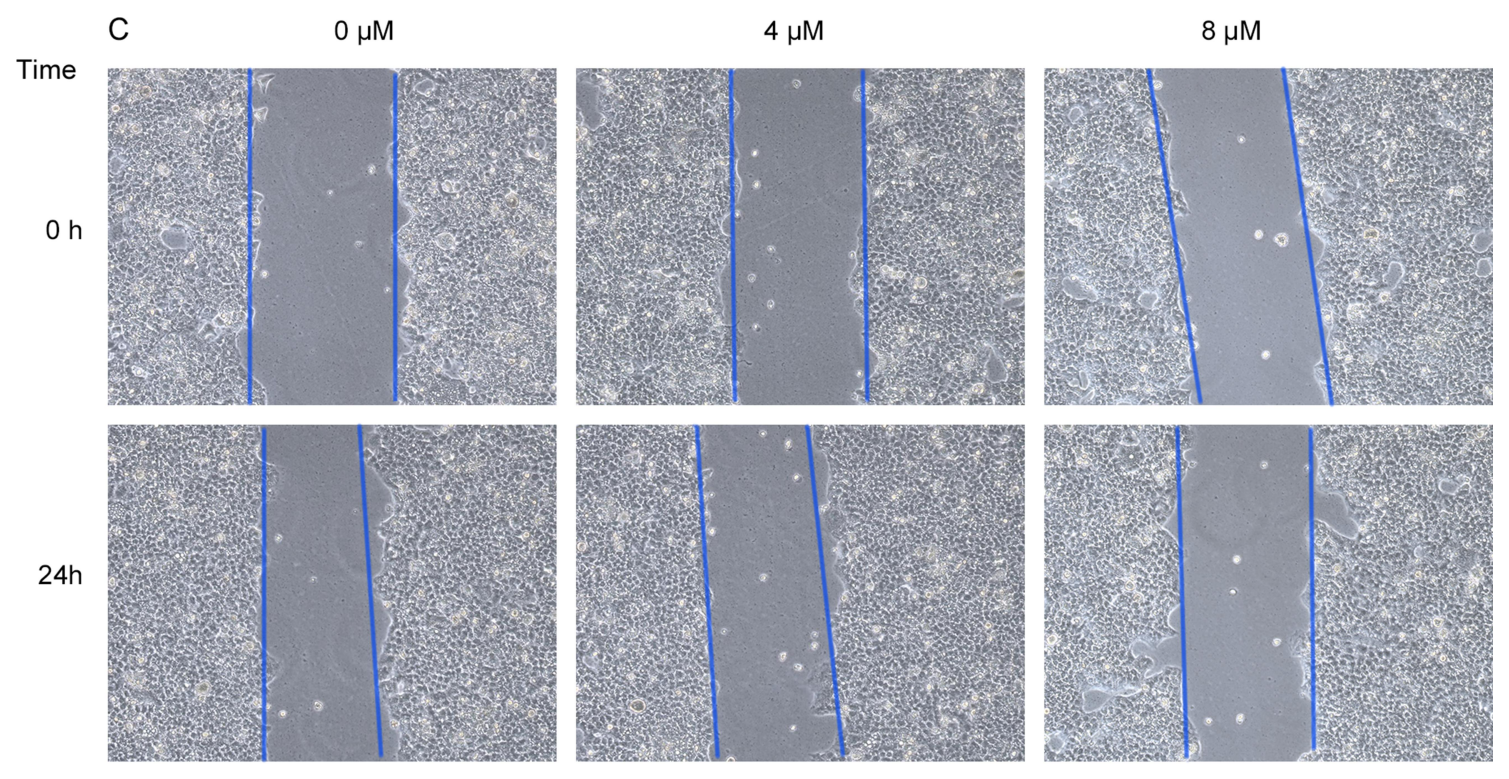

Figure I I Inhibitory effects of VE-822 on GES I migration. The scratch width was reduced in a dose-dependent manner. 
$27 \mathrm{~b}-3 \mathrm{p} .^{33}$ In GC, high levels of $A T G 10$ expression is associated with good $\mathrm{OS}(P=4.3 \mathrm{e}-0.5$ and $\mathrm{HR}=0.68,95 \%$ CI: 0.57-0.82). ATG10 variants, including rs10514231, rs1864182, and rs1864183, are correlated with shorter OS in patients with non-small-cell lung cancer. ${ }^{34}$ However, Yuan reported that ATG10 rs1864182 and rs10514231 are associated with a lower risk of breast cancer. $^{35}$ The distinct mechanism of ATG10 in GC should be further explored because taking into account the poor nutrition status of GC patients and the role of autophagy in host energy supply.

The ATG4s family, includes four isoforms: $A T G 4 A, \mathrm{~B}$, $\mathrm{C}$, and D. The ATG4 family completes its role in autophagy by regulating LC3 activity in autophagosome maturation. During this process, ATG4 (mainly the $A T G 4 B$ ) cleaves the C-terminus of LC3/GABARAP leading to lipid conjugation. After autophagosome expansion and maturation, $A T G 4 B$ is reactivated to release LC3 from the membrane junction which leads to fusion of the engulfed contents and lysosomes. ${ }^{36}$ However, ATG4B actually promotes tumor cell migration or proliferation among several cancer types, including breast cancer, ${ }^{37}$ pancreatic ductal adenocarcinoma, ${ }^{38}$ colorectal cancer, ${ }^{39}$ and prostate cancer. ${ }^{40}$ When blocked using an inhibitor or miRNA of $A T G 4 B$, tumor cell proliferation was controlled and susceptibility towards chemotherapy was enhanced due to the repressed autophagy, in this process, pro-LC3 cannot be cleaved, and the fusion of the autophagosomes with lysosomes would also be obstructed, which means that downregulation of $A T G 4 B$ is helpful to cancer cell apoptosis. Well, this trend was also witnessed in the present study in Figure 11, in our study, the high $A T G 4 B$ expression correlated with inferior OS, however, when treated with VE-822, the mRNA level of $A T G 4 B$ was significantly declined. $A T G 4 C$ is responsible for LC3 lipidation and delipidation during starvation, and its function in tumors differs slightly. In breast cancer, $A T G 4 C$ is regulated in an ATM-dependent manner, drives mammosphere formation, and promotes breast cancer development. ${ }^{41}$ Well, in another study, the deficiency of ATG4C promotes the development of fibrosarcomas, which coincided with the outcomes of our study that the highlight expression of $A T G 4 C$ seems suppress the development of GC.

$A T G 7$ is another crucial protein for autophagosome formation through the canonical pathway, and it was proved that high $A T G 7$ expression level was associated with poor OS in patients with GC, and in this research,
ATG7 knockdown contributes to Tanshinone I-induced apoptosis in gastric cancer. ${ }^{42}$ Examination about the relationship between autophagy and the endoplasmic reticulum (ER) revealed that ER-induced autophagy could drive cells into S-phase to inhibit apoptosis, moreover, when cells were infected with ATG5 and ATG7 overexpression adenovirus, the cleaved caspase- 3 and cleaved caspase- 12 expressions were markedly reduced. ${ }^{43}$ Cerebral angiogenesis research showed that $A T G 7$ could upregulate expression of laminin-5, a major constituent of the vascular extracellular matrix, via $\mathrm{NF}-\kappa \mathrm{B}$ signaling and promote tube formation, supporting a role for $A T G 7$ in cell migration. ${ }^{44}$ From these previous data, it appears that $A T G 7$ has the function to promote cell proliferation, suppress apoptosis, and drive blood vessel generation. Our PCR results show that downregulation of $A T G 7$ expression following VE-822 treatment could significantly increase cancer cell apoptosis, which is consistent with the results of previous studies.

Kaplan-Meier plotter results show that high ATG12 correlates with poor OS in patients with GC. In the formation of autophagosome, ATG12 has three roles in this process, it functions as a ubiquitin-like module through conjugating to $A T G 5$, it forms an E3 complex with $A T G 5$ and $A T G 16$, and it interacts with $A T G 3$. Using a mouse model, it was previously demonstrated that ATG12 depletion led mice to develop obesity at a faster rate than in controls. $^{45}$ In tumor cells, ATG12 could lead to cell death in an autophagy-independent manner by regulating cancer metabolism and functioning as an oncogene capable of sustaining mitochondrial biogenesis. ATG12 is involved in nutrient metabolism and mitochondrial respiration, and decreasing ATG12 expression levels, by shATG12 infection, caused impaired metabolic activity and mitochondrial biogenesis in H1299 lung cancer and MDA-MB-231 breast cancer cells revealed by the declined Ki-67marked cells, lower speed of colonies formation and the weaken expression level of mitochondrial-localizing proteins and the master regulator of mitochondria, PGC1- $\alpha^{45}$ Therefore, ATG12 functions as an oncogene in the development of GC tumors, which is supported by the results of this study.

$A T G 16 L 1$, another key role of autophagosome formation, was reported has autophagy-independent antiinflammatory activities. ${ }^{46,47}$ However, genome wide association studies of $A T G 16 \mathrm{Ll}$ variants indicate that they may be risk factors for Crohn's disease. ${ }^{48,49}$ Previously, it was shown that miR-874 can downregulate 
ATG16L1 mRNA levels resulting in autophagy inhibition and sensitizing the response of GC to chemotherapy. ${ }^{50}$ These results are consistent with those presented in this study.

Compared with other autophagy-related proteins, TECPR1, which forms a complex with ATG5-12 to promote autophagosome maturation, was the most sensitive biomarker for prostate cancer. ${ }^{51}$ In our study, TECPRI overexpression correlated with poor OS in patients with GC patients, when the effective treatment VE-822 was applied, its level was downregulated (Figure 11).

Although there has already been much research about the role of autophagy in cancer, these biomarkers may exert adverse effects in different types of cancer. This comment can be demonstrated by the recent study of $\mathrm{Li}$ et al. ${ }^{52}$ In the results of their study, MKL1 could promote the proliferation of gastric cancer cell by inhibiting the expression of FOXP3 (the important regulator of Tregs) via miR-34a and the knockdown of FOXP3 was likely to exacerbate this phenomenon which indicated that FOXP3 was an oncogene in gastric cancer. However, another study of FOXP3 in breast cancer revealed that FOXP3 could activate P21, the inhibitor of cell cycle and therefore, retarded the proliferation of cancer cells and this certified the suppressive role of FOXP3 in breast cancer. ${ }^{53,54}$ Therefore, it is necessary to explore the special role of this kind of biomolecules in gastric cancer through a large amount of clinical samples to improve its overall survival. And the present study investigated the prognostic value of autophagy-related proteins for patients with GC and used in vitro experiments to verify above outcomes. These results presented here contribute to understanding of the molecular mechanism of GC development and progression and would be helpful in the development of treatments with improved efficacy.

\section{Disclosure}

The authors report no conflicts of interest in this work.

\section{References}

1. Torre LA, Bray F, Siegel RL, Ferlay J, Lortet-Tieulent J, Jemal A. Global cancer statistics, 2012. CA Cancer J Clin. 2015;65(2):87-108. doi:10.3322/caac. 21262

2. Jencks DS, Adam JD, Borum ML, Koh JM, Stephen S, Doman DB. Overview of current concepts in gastric intestinal metaplasia and gastric cancer. Gastroenterol Hepatol (N Y). 2018;14(2):92-101.

3. Ferlay J, Soerjomataram I, Dikshit R, et al. Cancer incidence and mortality worldwide: sources, methods and major patterns in GLOBOCAN 2012. Int $J$ Cancer. 2015;136(5):E359-386. doi:10. $1002 /$ ijc. 29210
4. Karimi P, Islami F, Anandasabapathy S, Freedman ND, Kamangar F. Gastric cancer: descriptive epidemiology, risk factors, screening, and prevention. Cancer Epidemiol Biomarkers Prev. 2014;23 (5):700-713. doi:10.1158/1055-9965.EPI-13-1057

5. Levine B, Klionsky DJ. Development by self-digestion: molecular mechanisms and biological functions of autophagy. Dev Cell. 2004;6 (4):463-477. doi:10.1016/S1534-5807(04)00099-1

6. Ravikumar B, Sarkar S, Davies JE, et al. Regulation of mammalian autophagy in physiology and pathophysiology. Physiol Rev. 2010;90 (4):1383-1435. doi:10.1152/physrev.00030.2009

7. Wang L, Ye X, Zhao T. The physiological roles of autophagy in the mammalian life cycle. Biol Rev Camb Philos Soc. 2019;94 (2):503-516. doi:10.1111/brv.12464

8. Zhang HM, Li H, Wang GX, et al. MKL1/miR-5100/CAAP1 loop regulates autophagy and apoptosis in gastric cancer cells. Neoplasia. 2020;22(5):220-230. doi:10.1016/j.neo.2020.03.001

9. Guo JY, Xia B, White E. Autophagy-mediated tumor promotion. Cell. 2013;155(6):1216-1219. doi:10.1016/j.cell.2013.11.019

10. White E. Deconvoluting the context-dependent role for autophagy in cancer. Nat Rev Cancer. 2012;12(6):401-410. doi:10.1038/nrc3262

11. Ashrafi G, Schwarz TL. The pathways of mitophagy for quality control and clearance of mitochondria. Cell Death Differ. 2013;20 (1):31-42. doi:10.1038/cdd.2012.81

12. Lippai M, Low P. The role of the selective adaptor p62 and ubiquitin-like proteins in autophagy. Biomed Res Int. 2014;20 14:832704. doi:10.1155/2014/832704

13. Alemu EA, Lamark T, Torgersen KM, et al. ATG8 family proteins act as scaffolds for assembly of the ULK complex: sequence requirements for LC3-interacting region (LIR) motifs. J Biol Chem. 2012;287(47):39275-39290. doi:10.1074/jbc.M112.378109

14. Chen Y, Klionsky DJ. The regulation of autophagy - unanswered questions. J Cell Sci. 2011;124(Pt 2):161-170. doi:10.1242/jcs.064576

15. Dong X, Wang Y, Zhou Y, Wen J, Wang S, Shen L. Aquaporin 3 facilitates chemoresistance in gastric cancer cells to cisplatin via autophagy. Cell Death Discov. 2016;2:16087. doi:10.1038/ cddiscovery.2016.87

16. Qian HR, Yang Y. Functional role of autophagy in gastric cancer. Oncotarget. 2016;7(14):17641-17651. doi:10.18632/oncotarget.7508

17. Qu B, Yao L, Ma HL, Chen HL, Zhang Z, Xie J. Prognostic significance of autophagy-related proteins expression in resected human gastric adenocarcinoma. J Huazhong Univ Sci Technolog Med Sci. 2017;37(1):37-43. doi:10.1007/s11596-017-1691-2

18. Yoshioka A, Miyata H, Doki Y, et al. LC3, an autophagosome marker, is highly expressed in gastrointestinal cancers. Int J Oncol. 2008;33(3):461-468.

19. Kang MR, Kim MS, Oh JE, et al. Frameshift mutations of autophagy-related genes ATG2B, ATG5, ATG9B and ATG12 in gastric and colorectal cancers with microsatellite instability. J Pathol. 2009;217(5):702-706. doi:10.1002/path.2509

20. Takamura A, Komatsu M, Hara T, et al. Autophagy-deficient mice develop multiple liver tumors. Genes Dev. 2011;25(8):795-800. doi:10.1101/gad.2016211

21. Capparelli C, Guido C, Whitaker-Menezes D, et al. Autophagy and senescence in cancer-associated fibroblasts metabolically supports tumor growth and metastasis via glycolysis and ketone production. Cell Cycle. 2012;11(12):2285-2302. doi:10.4161/cc.20718

22. An CH, Kim MS, Yoo NJ, Park SW, Lee SH. Mutational and expressional analyses of ATG5, an autophagy-related gene, in gastrointestinal cancers. Pathol Res Pract. 2011;207(7):433-437. doi:10.1016/j.prp.2011.05.002

23. Kim JS, Bae GE, Kim KH, et al. Prognostic significance of LC3B and p62/SQSTM1 expression in gastric adenocarcinoma. Anticancer Res. 2019;39(12):6711-6722. doi:10.21873/anticanres.13886

24. Ieni A, Cardia R, Giuffre G, Rigoli L, Caruso RA, Tuccari G. Immunohistochemical expression of autophagy-related proteins in advanced tubular gastric adenocarcinomas and its implications. Cancers (Basel). 2019;11:3. doi:10.3390/cancers11030389 
25. Ni F, Tang H, Wang C, et al. Berzosertib (VE-822) inhibits gastric cancer cell proliferation via base excision repair system. Cancer Manag Res. 2019;11:8391-8405. doi:10.2147/CMAR. S217375

26. Metlagel Z, Otomo C, Takaesu G, Otomo T. Structural basis of ATG3 recognition by the autophagic ubiquitin-like protein ATG12. Proc Natl Acad Sci U S A. 2013;110(47):18844-18849. doi:10.1073/ pnas. 1314755110

27. Radoshevich L, Murrow L, Chen N, et al. ATG12 conjugation to ATG3 regulates mitochondrial homeostasis and cell death. Cell. 2010;142(4):590-600. doi:10.1016/j.cell.2010.07.018

28. Huang W, Zeng C, Hu S, Wang L, Liu J. ATG3, a target of miR-431$5 \mathrm{p}$, promotes proliferation and invasion of colon cancer via promoting autophagy. Cancer Manag Res. 2019;11:10275-10285. doi:10. 2147/CMAR.S226828

29. Kang Y, Jia Y, Wang Q, et al. Long noncoding RNA KCNQ1OT1 promotes the progression of non-small cell lung cancer via regulating miR-204-5p/ATG3 axis. Onco Targets Ther. 2019;12:10787-10797. doi:10.2147/OTT.S226044

30. Otomo C, Metlagel Z, Takaesu G, Otomo T. Structure of the human ATG12 ATG5 conjugate required for LC3 lipidation in autophagy. Nat Struct Mol Biol. 2013;20(1):59-66. doi:10.1038/nsmb.2431

31. Yousefi S, Perozzo R, Schmid I, et al. Calpain-mediated cleavage of Atg5 switches autophagy to apoptosis. Nat Cell Biol. 2006;8 (10):1124-1132. doi:10.1038/ncb1482

32. Hernandez-Gea V, Ghiassi-Nejad Z, Rozenfeld R, et al. Autophagy releases lipid that promotes fibrogenesis by activated hepatic stellate cells in mice and in human tissues. Gastroenterology. 2012;142 (4):938-946. doi:10.1053/j.gastro.2011.12.044

33. Jo YK, Kim SC, Park IJ, et al. Increased expression of ATG10 in colorectal cancer is associated with lymphovascular invasion and lymph node metastasis. PLoS One. 2012;7(12):e52705. doi:10.1371/ journal.pone. 0052705

34. Xie K, Liang C, Li Q, et al. Role of ATG10 expression quantitative trait loci in non-small cell lung cancer survival. Int $J$ Cancer. 2016;139(7):1564-1573. doi:10.1002/ijc.30205

35. Qin Z, Xue J, He Y, et al. Potentially functional polymorphisms in $A T G 10$ are associated with risk of breast cancer in a Chinese population. Gene. 2013;527(2):491-495. doi:10.1016/j.gene.2013.06. 067

36. Agrotis A, Ketteler R. On ATG4B as drug target for treatment of solid tumours-the knowns and the unknowns. Cells. 2019;9:1. doi:10.3390/cells9010053

37. Bortnik S, Choutka C, Horlings HM, et al. Identification of breast cancer cell subtypes sensitive to ATG4B inhibition. Oncotarget. 2016;7(41):66970-66988. doi:10.18632/oncotarget.11408

38. Yang A, Herter-Sprie G, Zhang H, et al. Autophagy sustains pancreatic cancer growth through both cell-autonomous and nonautonomous mechanisms. Cancer Discov. 2018;8(3):276-287. doi:10.1158/ 2159-8290.CD-17-0952

39. Liu PF, Leung CM, Chang YH, et al. ATG4B promotes colorectal cancer growth independent of autophagic flux. Autophagy. 2014;10 (8):1454-1465. doi:10.4161/auto.29556
40. Blessing AM, Rajapakshe K, Bollu Reddy L, et al. Transcriptional regulation of core autophagy and lysosomal genes by the androgen receptor promotes prostate cancer progression. Autophagy. 2017;13 (3):506-521. doi:10.1080/15548627.2016.1268300

41. Antonelli M, Strappazzon F, Arisi I, et al. ATM kinase sustains breast cancer stem-like cells by promoting ATG4C expression and autophagy. Oncotarget. 2017;8(13):21692-21709.

42. Jing X, Xu Y, Cheng W, Guo S, Zou Y, He L. Tanshinone I induces apoptosis and pro-survival autophagy in gastric cancers. Cancer Chemother Pharmacol. 2016;77(6):1171-1181. doi:10.1007/s00280016-3034-6

43. Zheng W, Xie W, Yin D, Luo R, Liu M, Guo F. ATG5 and ATG7 induced autophagy interplays with UPR via PERK signaling. Cell Commun Signal. 2019;17(1):42. doi:10.1186/s12964-019-0353-3

44. He L, Wei JY, Liu DX, Zhao WD, Chen YH. Atg7 silencing inhibits laminin-5 expression to suppress tube formation by brain endothelial cells. Anat Rec (Hoboken). 2019;302(12):2255-2260. doi:10.1002/ ar. 24223

45. Malhotra R, Warne JP, Salas E, Xu AW, Debnath J. Loss of Atg12, but not Atg5, in pro-opiomelanocortin neurons exacerbates diet-induced obesity. Autophagy. 2015;11(1):145-154.

46. Saitoh T, Fujita N, Jang MH, et al. Loss of the autophagy protein Atg16L1 enhances endotoxin-induced IL-1beta production. Nature. 2008;456(7219):264-268. doi:10.1038/nature07383

47. Sorbara MT, Ellison LK, Ramjeet M, et al. The protein ATG16L1 suppresses inflammatory cytokines induced by the intracellular sensors Nod1 and Nod2 in an autophagy-independent manner. Immunity. 2013;39(5):858-873. doi:10.1016/j.immuni.2013.10.013

48. Kuballa P, Huett A, Rioux JD, Daly MJ, Xavier RJ. Impaired autophagy of an intracellular pathogen induced by a Crohn's disease associated ATG16L1 variant. PLoS One. 2008;3(10):e3391. doi:10. 1371/journal.pone. 0003391

49. Rioux JD, Xavier RJ, Taylor KD, et al. Genome-wide association study identifies new susceptibility loci for Crohn disease and implicates autophagy in disease pathogenesis. Nat Genet. 2007;39 (5):596-604. doi:10.1038/ng2032

50. Huang H, Tang J, Zhang L, Bu Y, Zhang X. miR-874 regulates multiple-drug resistance in gastric cancer by targeting ATG16L1. Int J Oncol. 2018;53(6):2769-2779.

51. Bull JH, Ellison G, Patel A, et al. Identification of potential diagnostic markers of prostate cancer and prostatic intraepithelial neoplasia using cDNA microarray. Br J Cancer. 2001;84(11):1512-1519. doi:10.1054/bjoc.2001.1816

52. Li JP, Liao XH, Xiang Y, et al. MKL1/miR34a/FOXP3 axis regulates cell proliferation in gastric cancer. $J$ Cell Biochem. 2018.

53. Liu R, Wang L, Chen G, et al. FOXP3 up-regulates p21 expression by site-specific inhibition of histone deacetylase 2 /histone deacetylase 4 association to the locus. Cancer Res. 2009;69(6):2252-2259. doi:10.1158/0008-5472.CAN-08-3717

54. Zhang W, Liu R, Tang C, et al. PFTK1 regulates cell proliferation, migration and invasion in epithelial ovarian cancer. Int $J$ Biol Macromol. 2016;85:405-416. doi:10.1016/j.ijbiomac.2016.01.009

\section{Publish your work in this journal}

Cancer Management and Research is an international, peer-reviewed open access journal focusing on cancer research and the optimal use of preventative and integrated treatment interventions to achieve improved outcomes, enhanced survival and quality of life for the cancer patient.
The manuscript management system is completely online and includes a very quick and fair peer-review system, which is all easy to use. Visit http://www.dovepress.com/testimonials.php to read real quotes from published authors. 